\title{
Development and evaluation of an operational SDS forecasting system for East Asia: CUACE/Dust
}

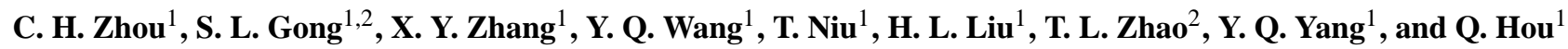 \\ ${ }^{1}$ Centre for Atmosphere Watch \& Services (CAWAS), Chinese Academy of Meteorological Sciences, China Meteorological \\ Administration (CMA), Beijing 100081, China \\ ${ }^{2}$ Air Quality Research Division, Science \& Technology Branch, Environment Canada, 4905 Dufferin Street, Toronto, Ontario \\ M3H 5T4, Canada
}

Received: 27 March 2007 - Published in Atmos. Chem. Phys. Discuss.: 8 June 2007

Revised: 3 January 2008 - Accepted: 18 January 2008 - Published: 18 February 2008

\begin{abstract}
CUACE/Dust, an operational mesoscale sand and dust storm (SDS) forecasting system for East Asia, has been developed by online coupling a dust aerosol emission scheme and dust aerosol microphysics onto a regional meteorological model with improved advection and diffusion schemes and a detailed Northeast Asia soil erosion database. With improved initial dust aerosol conditions through a 3-DVar data assimilation system, CUACE/Dust successfully forecasted most of the 31 SDS processes in East Asia. A detailed comparison of the model predictions for the 8-12 March SDS process with surface network observations and lidar measurements revealed a robust forecasting ability of the system. The time series of the operationally forecasted dust concentrations for a number of representative stations for the whole spring 2006 (1 March-31 May) were evaluated against surface PM10 monitoring data, showing a good agreement in terms of the SDS timing and magnitudes at and near the source regions where dust aerosols dominate. For the operational forecasts of spring 2006 in East Asia, a TS (threat score) system evaluated the performance of CUACE/Dust against all available observations and rendered a spring averaged TS value of 0.31 for FT1 ( $24 \mathrm{~h}$ forecasts), 0.23 for FT2 ( $48 \mathrm{~h}$ forecasts) and 0.21 for FT3 ( $72 \mathrm{~h}$ forecasts).
\end{abstract}

\section{Introduction}

As a natural weather phenomenon, sand and dust storm plays an important role in global climate change. SDS throughout Asia, Middle East and Northern Africa are estimated to cycle more than 200 to $5000 \mathrm{Mt} /$ year of mineral dust into

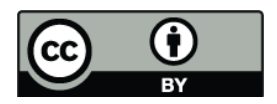

Correspondence to: C. H. Zhou (zhouch@cma.gov.cn) the earth's atmosphere (Tegen and Fung, 1994) with a total emission of about $800 \mathrm{Mt} /$ year from Asia alone (Zhang et al., 1997). Its global radiative forcing is estimated to be $-0.3 \sim 0.1 \mathrm{~W} \mathrm{~m}^{-2}$ with great uncertainties (IPCC, 2007). Sand and dust storms can directly cause low atmospheric visibility, thus impact the commercial and military operations and people's daily life in the dust prone regions. In these regions, the surface vegetation can also be destroyed when the plants are covered with heavy mineral particles or have been blown up by strong sandy wind during a SDS. Unlike coarse mineral particles which can deposit quickly in and near the source regions, finer dust particles can be suspended in the air for a longer time and more easily engaged in long range transports. They can also take in or be taken by other aerosols like black carbon (BC), organic carbon (OC) or sulfate during the transports. These finer particles, especially with the diameter less than $10 \mu \mathrm{m}$, can be freely inhaled into human bodies to cause health problems. A severe SDS could be a disaster like the one with visibility less than $50 \mathrm{~m}$ occurred on 5 May 1995 in Jin Chang, Gansu province of northwest China which caused 85 fatalities and 31 missing (Qian et al., 1996). The frequency of SDS ranges from one day per year in most part of North China to about 100 days per year in places near the desert like Yan Chi (Zhou, 2001). Although with a great interannual variability (Gong et al., 2006), most Asia SDS occurs in spring time (Sun et al., 2001). Due to the difficulty to fight against a SDS, a very effective way to alleviate its impacts is to issue forecast and early warning information for those dust prone regions.

Early SDS forecasts were made through the analysis of cold air mass movements from the weather chart without considering the emission, surface feature and transports of dust due to computational restrains, which had resulted in many errors or discrepancies. In the last decade, many

Published by Copernicus Publications on behalf of the European Geosciences Union. 
attempts have been made to numerically simulate and forecast SDS. Those models, including NARCM (Gong et al., 2003b) from Canada, DREAM from Spain (Pe'rez et al., 2006) and CFORS (Uno et al., 2001) in Japan, have limited success to model the SDS occurrence, transports and depositions. Because of the varieties of dust emission schemes, horizontal and vertical resolutions, numerical methods, and different meteorological models, eight models in the DMIP project from different countries show quite different performance for Asian dust episodes in March and April of 2003 in terms of flux, transport, horizontal and vertical distribution outputs (Uno et al., 2006). This has posed a great challenge to use these models in the operational or real time SDS forecasts as an operational forecast requires operation stability, effective forecast lead time and the average accuracy in terms of routine meteorology inputs and relatively fixed model configurations and database. Using a 4-DVar (4-Dimensional Variation) data assimilation method and NIES lidar observations, Yumimoto et al. (2007) has proposed an inverse scheme to improve the dust emission for an extreme SDS process and has mitigated the underestimate of dust concentrations and vertical profiles of the SDS. Even though this 4-DVar technique has not been used in operational forecasts, it has certainly shed some lights in improving the operational forecasts and general simulation of a SDS.

This paper presents a real time SDS forecasting system - CUACE/Dust (Chinese Unified Atmospheric Chemistry Environment - Dust) developed by coupling a dust aerosol emission and aerosol micro-physics module onto a mesoscale meteorological model with an improved SDS vertical diffusion and a 3-D advection scheme. With CUACE/Dust, three-day SDS real time forecasts and early warning information have been issued in spring time from March to May in East Asia since 2005. Many insights of SDS forecasts have been achieved through the operational forecasts with respect to the emission scheme, improved advection and transport schemes, and the 3-Dvar (3-Dimensional Variation) SDS data assimilation system. A typical severe SDS process has been selected to evaluate the model forecasting ability on its onset, development, transport and vertical distribution by comparing with the weather station SDS records and vertical structure from lidar observations. Then the quantitative forecasting ability is analyzed and evaluated against the surface PM10 concentrations in 5 representative stations for the whole spring dust season in 2006. The model average forecasting ability in the results-domain was also analyzed through a SDS TS scoring system.

\section{Description of CUACE/Dust}

CUACE has been designed as a unified chemistry module to be easily coupled onto any atmospheric models at various temporal and spatial scales. Through a common interface to communicate with a host model, CAUCE has four functional blocks (Gong and Zhang, 2007): (1) an emission processor, (2) a gas phase chemistry, (3) an aerosol algorithm and (4) a data assimilation system. This paper focuses on the application of CUACE in SDS forecasts.

\subsection{Dust aerosol in CUACE}

The aerosol module currently in CUACE is a size-segregated multi-component algorithm for different types of aerosols including dust, sea salt, BC/OC and sulfate (Gong et al., 2003a) with major aerosol processes in the atmosphere such as the generation, hygroscopic growth, coagulation, nucleation, condensation, dry depositions, scavenging and aerosol activations. Since most mineral aerosol is primarily emitted from dry land surface in coarse mode (Zhao et al., 2003), the processes of coagulation, nucleation, condensation and aerosol activations have been omitted for mesoscale dust simulation and forecast in CUACE/Dust.

Particle size distribution plays an important role in aerosol microphysics and its large scale transport processes. Studies (Zhang et al., 2003) show that the dominant mass of the mineral aerosols in Northeast Asia was with diameters from 2 to $20 \mu \mathrm{m}$ which accounts for about $53 \%-68 \%$ of the total mineral dust. It may shift slightly to course mode in heavy dust storms near the source regions and to fine mode in receptor regions. Consequently, the dust aerosol size spectra in CUACE/Dust have been divided into 12 size bins with a radius range of $0.005-0.01,0.01-0.02,0.02-0.04,0.04$ $0.08,0.08-0.16,0.16-0.32,0.32-0.64,0.64-1.28,1.28$ $2.56,2.56-5.12,5.12-10.24,10.24-20.48 \mu \mathrm{m}$, respectively.

\subsection{Dust emission schemes and soil erosion database}

There are two dust emission schemes built in CUACE/Dust: (1) by Marticorena and Bergametti (1995), Alfaro et al. (1997), Alfaro and Gomes (2001) (hereinafter referred to as MBA) and (2) by Shao $(2001,2004)$. Both of these schemes require a comprehensive soil erosion database, which contains deserts and semi-deserts distributions, soil grain-size, soil moisture content, snow cover, landuse and surface roughness length. For East Asia, parameters and data sets to drive these two schemes have been derived and compared (Zhao et al., 2006) . In the current operational CUACE/Dust, the MBA scheme is used. A detailed desert distribution and soil texture data base for China was given (Gong et al., 2003b) and the snow cover was retrieved from NOAA17 AVHHR at the resolution of $0.02^{\circ} \times 0.02^{\circ}$.

\subsection{Meteorology, transports and data assimilation}

The key parameters from a host model to drive CUACE/Dust are the 3-D winds, boundary-layer turbulence, surface fluxes, cloud and precipitation as well as the soil moisture contents. They determine not only the production of dust aerosol but also its long-range transports. In the current CUACE/Dust, a 


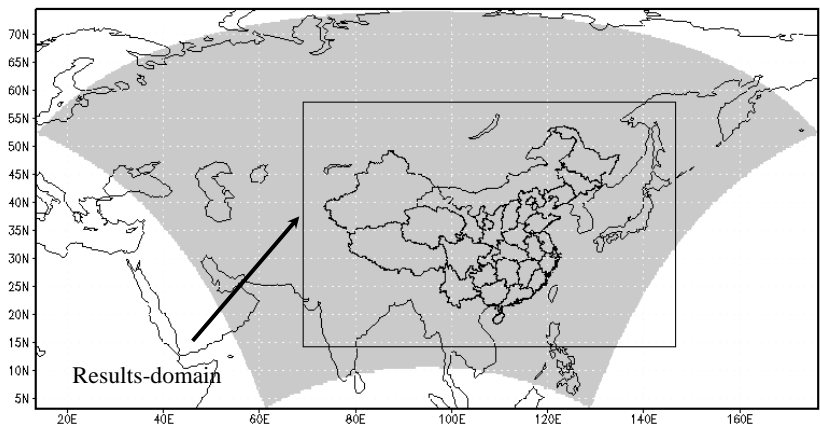

Fig. 1. The shaded area is the CUACE/Dust model domain and the results domain inside it is the area where all the results are analyzed.

nonhydrostatic version of MM5 was used as the meteorological driver with a horizontal dimension of $68 \times 85$ and a resolution of $108 \mathrm{~km}$ to cover Asia and east part of Europe (Fig. 1). There are 24 vertical sigma-levels up to $100 \mathrm{hpa}$ with the values for each one as 1.0, 0.996, 0.992, 0.986, 0.980, 0.970, $0.955,0.930,0.900,0.860,0.810,0.760,0.710,0.660,0.600$, $0.530,0.460,0.390,0.320,0.250,0.180,0.110,0.050$ and 0 . Meteorological forecasts in twelve hours interval from T213, an operational global medium range spectrum model at the resolution of $0.625^{\circ}$ in CMA, are interpolated to formulate the meteorological initial, boundary and lateral conditions.

There are a number of improvements done to the host MM5 model to provide more reasonable parameters to drive the dust forecasts. A Multi-dimensional Positive Definite Advection Transport Algorithm (MPDATA) (Smolarkiewicz, 2006) has been introduced as the advection scheme for all tracers due to its stability, consistence and conservation for positive definiteness. The excess numerical diffusion produced by this scheme is corrected by reapplying the scheme in which the velocity would be replaced by an anti-diffusion velocity field derived analytically from the truncation error analysis of the upstream scheme. A nonscillatory option can also be applied to assure monotonicity. Two iterations would make the MPDATA second-order-accurate in time and space.

Vertical diffusion in sub-grid scale is another important progress controlling the transports of tracers, especially in PBL. A nonlocal vertical diffusion scheme has been adopted in CUACE/Dust which is an improved approach from local-k method based on local gradients of wind and potential temperature. The new method overcame the deficiencies for highly unstable conditions where the local gradients cannot model the transport by large eddies representing the bulk property of the whole PBL (Hong and Pan, 1996).

One of the unique features in CUACE/Dust is the implementation of a three dimensional data assimilation model that uses the observations of the surface monitoring networks and FY-2C SDS retrieval data (Hu et al., 2007; Niu et al., 2007). The assimilated output has been used as the real time initial dust concentrations in the forecasting system.
Table 1. SDS contingency table.

\begin{tabular}{|c|c|c|c|}
\hline & \multicolumn{3}{|c|}{ SDS Observed } \\
\hline \multirow{3}{*}{ 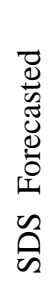 } & & YES & NO \\
\hline & YES & NA & NB \\
\hline & NO & NC & ND \\
\hline
\end{tabular}

\subsection{Threat Score (TS) system for CUACE/Dust}

In order to evaluate the performance of the CUACE/Dust, a threat scoring system was developed where observations from various sources concerning dust aerosol in China have been integrated into a GIS (Geographic Information System) (Wang et al., 2007). Surface regular weather phenomenon which can directly report the occurrence of a SDS and satellite retrieved IDDI (Hu et al., 2007) with an value above 20 defined as a SDS were used to construct the observational truth of a SDS or non-SDS. However, both surface SDS record and satellite retrieved IDDI were separately mapped into a $1^{\circ} \times 1^{\circ}$ grid and the IDDI index was used only when there is no surface monitoring data in that grid. Using the forecasted surface dust concentration of $200 \mu \mathrm{g} \mathrm{m}^{-3}$ as the threshold for a SDS and a contingency table (Table 1), forecasted results from any sub-domain or a SDS process can be evaluated by the following categories:

$$
\begin{array}{ll}
\text { Threat Score: } & \mathrm{TS}=\frac{\mathrm{NA}}{\mathrm{NA}+\mathrm{NB}+\mathrm{NC}} \\
\text { Miss Ratio: } & \mathrm{MR}=\frac{\mathrm{NC}}{\mathrm{NA}+\mathrm{NC}} \\
\text { False Alarm: } & \mathrm{FAR}=\frac{\mathrm{NB}}{\mathrm{NA}+\mathrm{NB}} \\
\text { Forecast Accuracy: } \mathrm{AC}=\frac{\mathrm{NA}+\mathrm{ND}}{\mathrm{NA}+\mathrm{NB}+\mathrm{NC}+\mathrm{ND}}
\end{array}
$$

The scoring system was run every day to compute values for the above categories. For any individual SDS process, a TS value is averaged over its lasting period. A TS value for any sub-domain is estimated by averaging all the daily scores for both SDS processes and non-SDS days in the spring.

\section{Results and evaluation}

Forecasting results for spring 2006 were evaluated and compared with available observation data across East Asia (Wang 
(a)

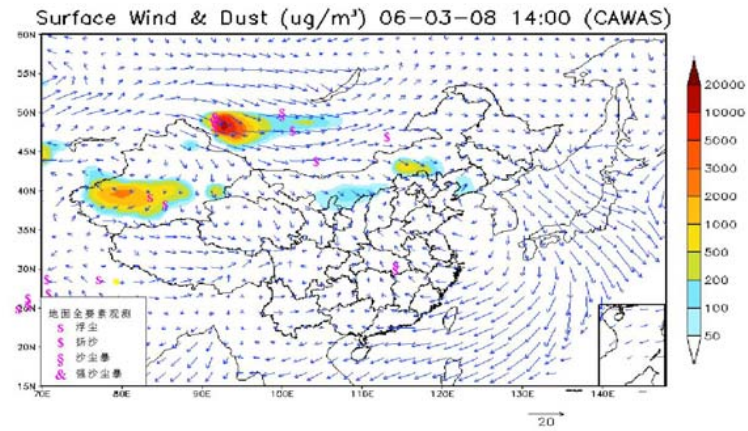

(b)

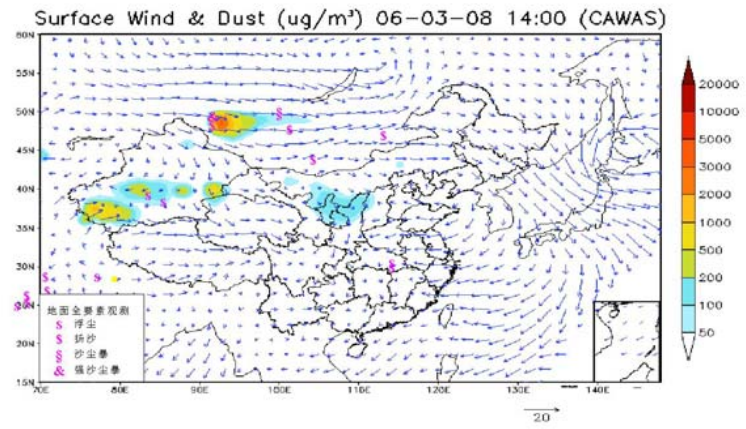

(c)

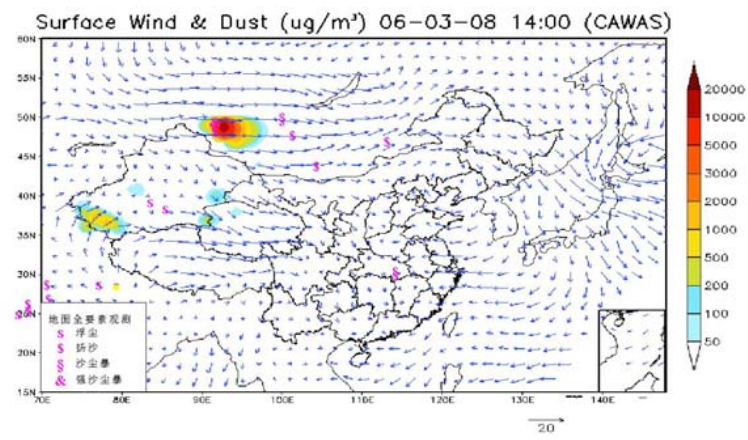

Fig. 2. Surface snap SDS concentrations and wind field at $14 \mathrm{~h}$ on 8 March at lead time of (a) 54, (b) 30 and (c) $6 \mathrm{~h}$ from the initial forecast time of $8 \mathrm{~h}$ on 6, 7 and 8 March, respectively (Beijing standard time used, shortly in BST). The scattered pink signals $\mathrm{S}, \$, \S$ and \& represent observation records of floating dust, blowing dust, SDS and severe SDS respectively from weather stations at the same local time.

et al., 2007). Analysis of synoptic weather patterns associated with the dust storms for spring 2006 was also investigated, which defined a SDS process according to certain criteria (Yang et al., 2007) . Based on Yang's definition, there were 31 SDS processes occurred from 1 March to 31 May 2006 in Northeast (NE) Asia, among which 13 were Severe SDS processes, 12 were SDS processes and 6 were blowing dust processes ..(Zhang, 2006) (Table 2). The SDS process of 8-12 March has been chosen to evaluate the CUACE/Dust's performance on the forecast consistency of SDS onset and long-range transports for different lead time. Four lidar stations located in NE Asia, i.e. Shapotou $\left(104.95^{\circ} \mathrm{E}\right.$, $\left.37.46^{\circ} \mathrm{N}\right)$, Huhhot $\left(111.4^{\circ} \mathrm{E}, 40.9^{\circ} \mathrm{N}\right)$, Beijing $\left(116.17^{\circ} \mathrm{E}\right.$, $\left.39.56^{\circ} \mathrm{N}\right)$ and Tsukuba $\left(140.12^{\circ} \mathrm{E}, 36.05^{\circ} \mathrm{N}\right)$ from a lidar observation network (www-lidar.lies.go.jp) (Sugimoto et al., 2000) have also been chosen to evaluate the SDS vertical distributions over the deserts, near source areas and downwind of the SDS sources.

In order to quantitatively evaluate the CUACE/Dust system in NE Asia, PM10 observations from the CMA SDS operational network (Wang et al., 2007) have been chosen to compare with the forecasted DM40 (dust particle with the diameter less than $40 \mu \mathrm{m}$ ) at different lead time from 1 March to 31 May 2006. Based on the data quantity and station locations, five sites were selected to represent the source regions at Tazhong, Ejilaqi and Zhurihe, and the downwind areas at Beijing and Dalian.

In addition, TS scores for all the 31 SDS processes and spring mean TS for each grid in the results-domain have also been presented in the paper for the overall model evaluation in 2006 spring dust season.

\subsection{Evaluation of SDS process of 8-12 March 2006}

This severe SDS process started at 14:00 (BST) on 8 March in Mongolia, hit China massively from 9 March and ended at 02:00 (BST) on 12 March in Korea Peninsula. SDS phenomena have been observed in Mongolia and many places in China such as Inner Mongolia, Qinghai, Gansu, Ningxia, Shaanxi, Shanxi and Liaoning provinces. The black SDS phenomena have been observed in two stations: Zhurihe and Suniteyouqi, with zero visibility and wind speed exceeding $20 \mathrm{~m} / \mathrm{s}$ and in 3 other stations nearby with visibility less than $100 \mathrm{~m}$ in the area of Onqin Daga Sand Areas in the afternoon on 9 March. It is the first and one of the most severe SDS hit Northeast Asia in 2006.

Three real time forecasts started at $00 \mathrm{Z}$ of $6-8$ March by CUACE/Dust captured the onset of this process at 14:00 (BST) on 8 March originated from the west of Mongolia where a cold air mass has swept in. This is shown from the agreements between the surface SDS reports observed in this region and the surface dust concentration centers and the surface wind field from the model predictions at three different lead times (54h, $30 \mathrm{~h}$ and $6 \mathrm{~h}$ ) (Fig. 2). One day later, the forecasted results from the three lead time forecasts started at 00Z 7-9 March have also showed the peak SDS concentration was located in the south of Mongolia and Inner Mongolia of China, agreeing to the surface SDS observations in many stations over there after this process reached the class of a sever SDS at 14:00 (BST) on 9 March (Fig. 3).

Figure 4 shows the forecasting evolution of this SDS process starting at 00Z on 9 March for $72 \mathrm{~h}$. At 14:00 (BST) on 10 March (Fig. $4 \mathrm{~b}$ ), i.e. the lead time of $30 \mathrm{~h}$, the forecasted surface peak dust concentration matched the SDS records in the west of Inner Mongolia while the front of the SDS had reached Liaoning, Bohai sea, Shangdong, Hebei, Henan and Shanxi Provinces overlapped by surface records of blowing dust and floating dust. Six hours later at the lead time of 
Table 2. SDS processes in 2006 from March to May.

\begin{tabular}{|c|c|c|c|c|c|c|}
\hline DS Number & Date (MM.DD-DD) & Class & Influenced Regions & TS24 & TS48 & TS72 \\
\hline 1 & $3.3-4$ & SDS & Mongolia, West of Inner Mongolia & 0.07 & 0.07 & 0.07 \\
\hline 2 & $3.6-6$ & SDS & Center and SE of Mongolia & 0.04 & 0.04 & 0.01 \\
\hline 3 & $3.7-7$ & Blowing Dust & South West of Mongolia & 0.09 & 0.09 & 0.09 \\
\hline 4 & $3.8-12$ & Severe SDS & $\begin{array}{l}\text { Mongolia, NW, N, NE of China, Korea Peninsula, } \\
\text { and Japan }\end{array}$ & 0.55 & 0.34 & 0.29 \\
\hline 5 & $3.11-13$ & Severe SDS & Taklimakan basin & 0.54 & 0.26 & 0.21 \\
\hline 6 & $3.15-15$ & Blowing Dust & Onqin Daga & 0.6 & 0.2 & 0.17 \\
\hline 7 & $3.16-19$ & Blowing Dust & Mongolia, NW, N, NE of China, & 0.33 & 0.22 & 0.16 \\
\hline 8 & $3.21-21$ & Blowing Dust & $\begin{array}{l}\text { S of Mongolia, West of InnerMongolia and Ningxia } \\
\text { Province of China }\end{array}$ & 0.26 & 0.21 & 0.21 \\
\hline 9 & $3.23-25$ & Severe SDS & $\begin{array}{l}\text { Mongolia, West and Central of Inner Mongolia, N } \\
\text { and NE China, Korea Peninsula }\end{array}$ & 0.19 & 0.12 & 0.08 \\
\hline 10 & $3.26-28$ & Severe SDS & $\begin{array}{l}\text { Mongolia, West and Central of Inner Mongolia, N } \\
\text { and NE and Central China, Korea Peninsula }\end{array}$ & 0.19 & 0.14 & 0.1 \\
\hline 11 & $3.29-4.1$ & SDS & Monggolia, Central of Inner Mongolia, NW China & 0.22 & 0.23 & 0.22 \\
\hline 12 & $4.1-3$ & SDS & Mongolia & 0.24 & 0.24 & 0.25 \\
\hline 13 & $4.5-9$ & Severe SDS & $\begin{array}{l}\text { Center and South Mongolia, NW, N and NE China, } \\
\text { Korea Peninsula and Japan }\end{array}$ & 0.4 & 0.21 & 0.21 \\
\hline 14 & $4.8-9$ & SDS & $\mathrm{W}$ and SE of Mongolia, Centre of Inner Mongolia & 0.47 & 0.23 & 0.23 \\
\hline 15 & $4.9-11$ & Severe SDS & West of Mongolia, NW, $\mathrm{N}$ and NE of China & 0.49 & 0.37 & 0.35 \\
\hline 16 & $4.9-20$ & Severe SDS & Xinjiang of China & 0.4 & 0.29 & 0.27 \\
\hline 17 & $4.12-13$ & SDS & Mongolia, Centre of Inner Mongolia & 0.35 & 0.25 & 0.25 \\
\hline 18 & $4.14-15$ & Blowing dust & SW of Mongolia, NW and $\mathrm{N}$ of China & 0.5 & 0.24 & 0.25 \\
\hline 19 & $4.15-19$ & Severe SDS & $\begin{array}{l}\text { Mongolia, NW, N NE of China, Korea Peninsula } \\
\text { and Japan }\end{array}$ & 0.39 & 0.3 & 0.23 \\
\hline 20 & $4.20-25$ & Severe SDS & $\begin{array}{l}\text { Mongolia, NW, N NE of China, Korea Peninsula } \\
\text { and Japan }\end{array}$ & 0.33 & 0.24 & 0.23 \\
\hline 21 & $4.24-25$ & SDS & $\begin{array}{l}\text { West of Mongolia, NW and West of Inner Mongolia } \\
\text { of China }\end{array}$ & 0.41 & 0.3 & 0.33 \\
\hline 22 & $4.28-5.1$ & SDS & $\begin{array}{l}\text { Mongolia, NW, N NE of China, Korea Peninsula } \\
\text { and Japan }\end{array}$ & 0.3 & 0.2 & 0.19 \\
\hline 23 & $5.2-4$ & Severe SDS & Mongolia, part of West Inner Mongolia of China & 0.37 & 0.32 & 0.29 \\
\hline 24 & $5.5-6$ & SDS & $\begin{array}{l}\text { South and East of Mongolia, East of Mongolia and } \\
\text { NE of China }\end{array}$ & 0.42 & 0.37 & 0.37 \\
\hline 25 & $5.8-8$ & SDS & Mongolia & 0.49 & 0.44 & 0.36 \\
\hline 26 & $5.8-9$ & Blowing dust & Taklimakan basin of Xinjiang & 0.46 & 0.36 & 0.33 \\
\hline 27 & $5.10-11$ & SDS & Taklimakan basin of Xinjiang & 0.31 & 0.28 & 0.26 \\
\hline 28 & $5.15-17$ & Severe SDS & Mongolia, NW, $\mathrm{N}$ and $\mathrm{NE}$ of China & 0.3 & 0.23 & 0.18 \\
\hline 29 & $5.19-20$ & SDS & Mongolia, NW of China & 0.32 & 0.35 & 0.32 \\
\hline 30 & $5.23-24$ & Severe SDS & Centre and South of Mongolia & 0.29 & 0.25 & 0.25 \\
\hline 31 & $5.29-30$ & Severe SDS & Mongolia and Inner Mongolia & 0.46 & 0.34 & 0.3 \\
\hline
\end{tabular}

$36 \mathrm{~h}$ (Fig. 4c), the dust belt had moved to North Korea which was also agreed by the surface floating dust observations. At 14:00 (BST) on 11 March with the lead time of $54 \mathrm{~h}$ (Fig. 4d), part of the dust belt still stayed in the area of Shanxi, Henan, Jiangsu in China with floating dust and haze observed in the stations over there. Another part of the dust belt had reached South Korea where there were floating dusts observed in many stations. At 02:00 (BST) in the early morning of 12 March (Fig. 4f), there were a few floating dusts observed in southern end of South Korea, where the forecasted dust belt was also about to move out of this area.
The comparisons above showed that CUACE/Dust has produced consistent forecasts with different lead times. Like the conventional weather forecasts, the lead time accounts for the forecast difference and accuracy in dust concentration and meteorology and the influence of the initial assimilated SDS data. Generally speaking, a shorter lead time yields a better result than longer ones. This is partially due to the ability of a meso-scale model to accurately predict the meteorology as a function of time. Another reason for the difference comes mainly from the impact of SDS data assimilation. The 3-DVar system assimilates the real-time surface 
(a)

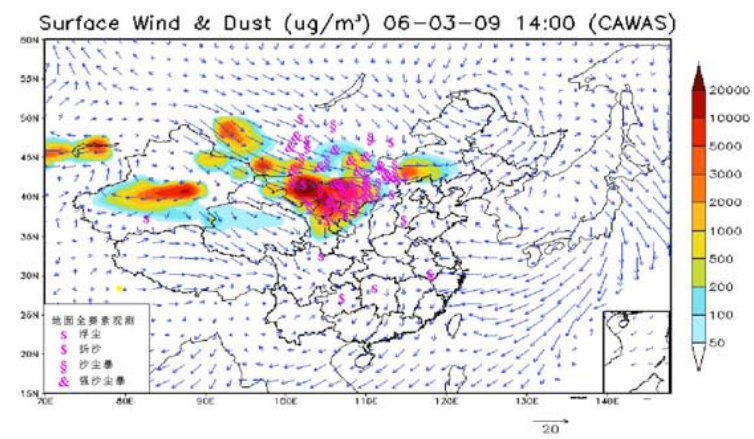

(b)

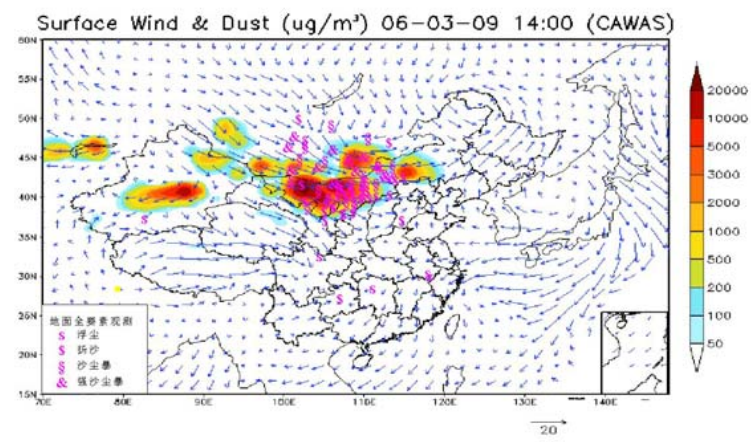

(c)

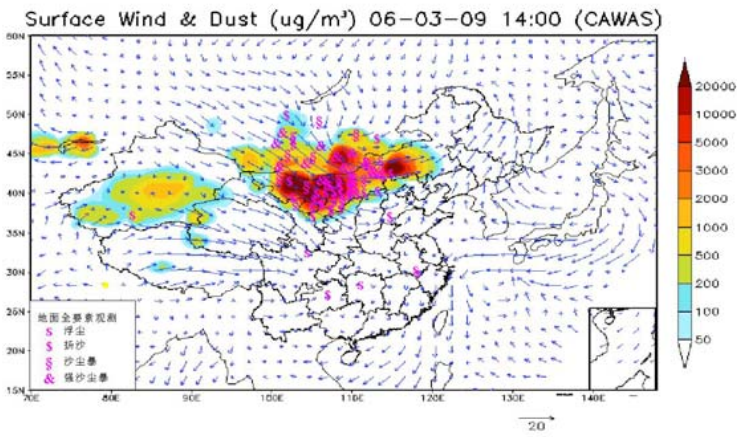

Fig. 3. Surface snap SDS concentrations and wind field at $14 \mathrm{~h}$ on 9 March at a lead time of (a) 54, (b) 30 and (c) $6 \mathrm{~h}$ from the initial forecast time of $8 \mathrm{~h}$ on 7, 8 and 9 March, respectively (BST).

SDS records and satellite retrieval SDS IDDI into the model to improve the initial SDS conditions. As the impact of 3Dvar initial conditions weakening with time, the wind filed will play a dominant role on the dust emission and transport. Due to this reason, both of the outputs at lead time of $30 \mathrm{~h}$ and $6 \mathrm{~h}$ have quite correctly forecasted the surface dust distribution and have little difference to each other (Fig. 3). More real SDS information and shorter lead time means more data assimilation impact on SDS distribution which was exactly true for the case with the initial forecasting time of $00 \mathrm{Z}$ on 9 March. Because of more surface and satellite observation information being added into the model, the dust concentration and distribution compared better with the surface SDS records than those by the other two with initial forecasting time of $00 \mathrm{Z}$ on 7 March and on 8 March when little SDS observation information was available.

To further explore the performance of CUACE/Dust, the time-height sectional plots for this dust process were also compared with lidar observations at four stations (Fig. 5). For Shapotou (Fig. 5a), a station in the south of Badain Juran Deserts, the predicted peak concentrations were mostly under $2000 \mathrm{~m}$, from $03 \mathrm{Z}$ in the morning to about $15 \mathrm{Z}$ in the night at each day from 9 to 12 March, agreeing with the lidar vertical profile observations in the station. Both the forecast and the observation have a diurnal cycle which starts at about $03 \mathrm{Z}$, reaches the maximum at about $12 \mathrm{Z}$ and then weakens, especially for the days of 9 March and 10 March. For Huhhot, a station to the east of Badain Juran Desert areas, the forecasted concentration peak of $10000 \mu \mathrm{g} \mathrm{m}^{-3}$ from $06 \mathrm{Z}$ to $12 \mathrm{Z}$ on $9 \mathrm{March}$ was located under $3000 \mathrm{~m}$ and mostly agreed with the lidar observation. While on 10 March, the forecasted daytime concentration peak with a value of $1000 \mu \mathrm{g} \mathrm{m}^{-3}$ was much weaker than that of the previous day and the peak lasted much shorter comparing with the lidar observation.

For Beijing, both model predictions and lidar observations showed that the dust storm was transported to Beijing through the upper air at about $10 \mathrm{Z}$ and settled down to the surface at about $15 \mathrm{Z}$ in the evening of 9 March with the dust concentration centers located between $2000-4000 \mathrm{~m}$ above the ground. On $10 \mathrm{March}$, lidar observation showed that more dust particles centered at about $3000 \mathrm{~m}$ high and stayed there from $03 \mathrm{Z}$ to $18 \mathrm{Z}$. This was only partially predicted by the model with shorter lasting time and relatively lower concentration. For Tsukuba in Japan, the dust transported to its upper air over with a much lower concentration of $500 \mu \mathrm{g} \mathrm{m}^{-3}$ from the forecasts at a height of about 1000 $6000 \mathrm{~m}$ after $12 \mathrm{Z}$ on 11 March which was also the ending time of this dust process from the surface weather stations on SDS.

\subsection{Comparisons with surface PM observations}

Three lead time forecasts $(\mathrm{FT} 1=24 \mathrm{~h}, \mathrm{FT} 2=28 \mathrm{~h}$ and FT3 $=72 \mathrm{~h}$ ) of daily averaged DM40 were compared with the daily observed PM10 at 5 stations for all spring 2006 (Fig. 6). In Tazhong of Takilimakan Desert, five SDS processes, i.e. DS5, DS16, DS26, DS27 and DS29, were observed (Table 2 and Fig. 6a). For the severe SDS process - DS5 on 12 March, all three forecasts were able to capture it. Comparing to the observed daily mean PM10 of $5011 \mu \mathrm{g} \mathrm{m}^{-3}$ for this case, the forecasted DM40 by three consecutive predictions had a daily average value of $4571 \mu \mathrm{g} \mathrm{m}^{-3}, 3538 \mu \mathrm{g} \mathrm{m}^{-3}$ and $1023 \mu \mathrm{g} \mathrm{m}^{-3}$, respectively. In another severe SDS process DS16, all three FTs had forecasted the process and the concentration peaks. FT1 forecasted a total dust concentration of $7363 \mu \mathrm{g} \mathrm{m}^{-3}$ which was rather comparable to the observed PM10 concentration of $6467 \mu \mathrm{g} \mathrm{m}^{-3}$. Generally speaking, the FT1 performed a little better than FT2 and FT3 in these 
(a)

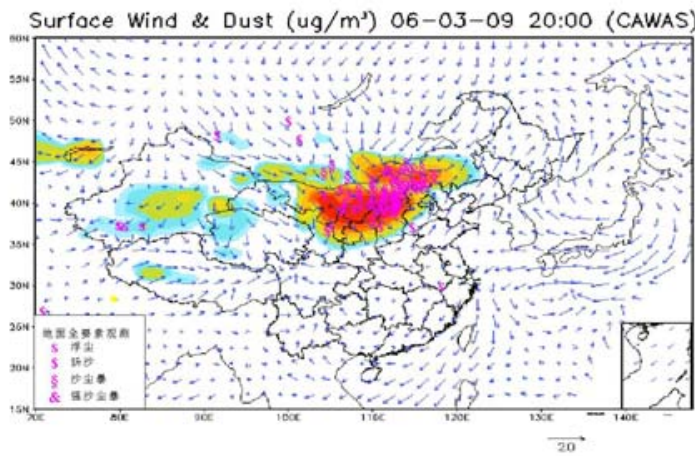

(b)

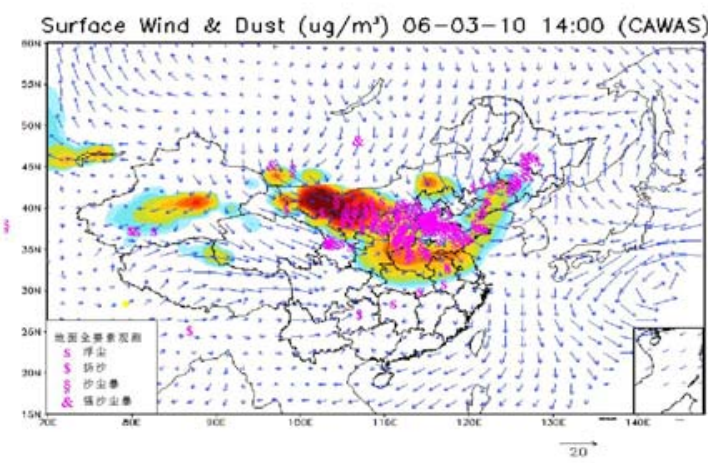

(c)

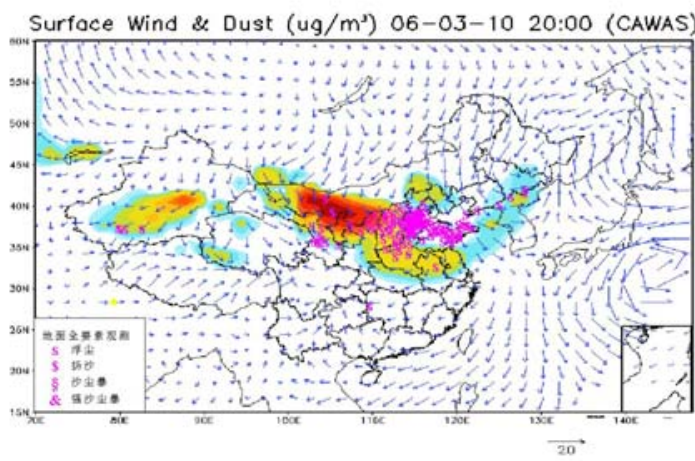

(d)

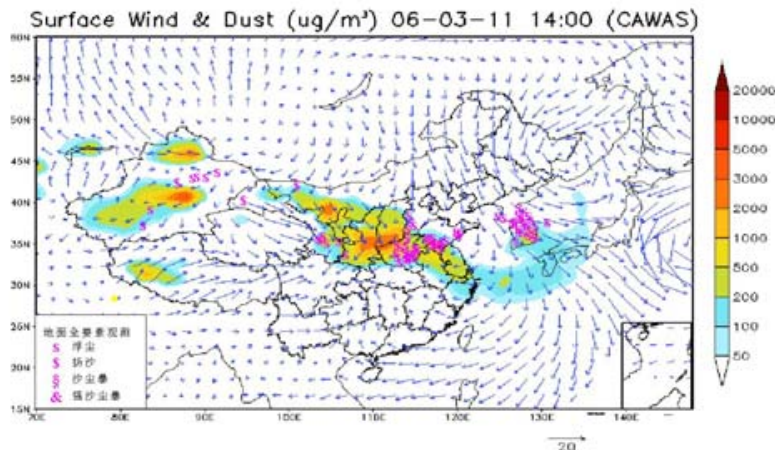

(e)

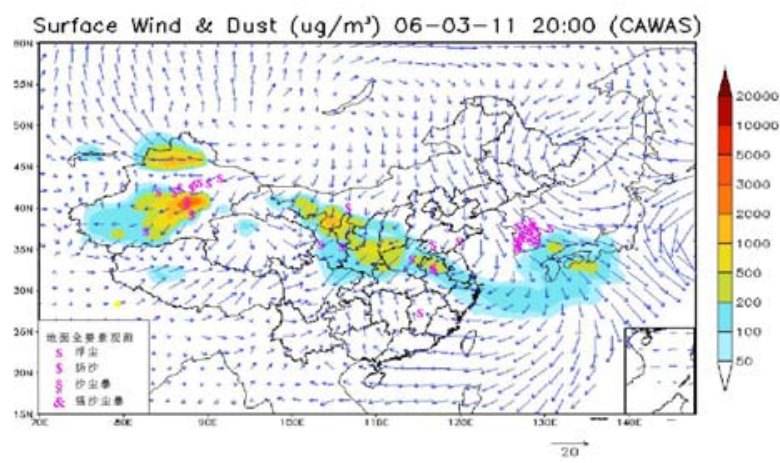

(f)

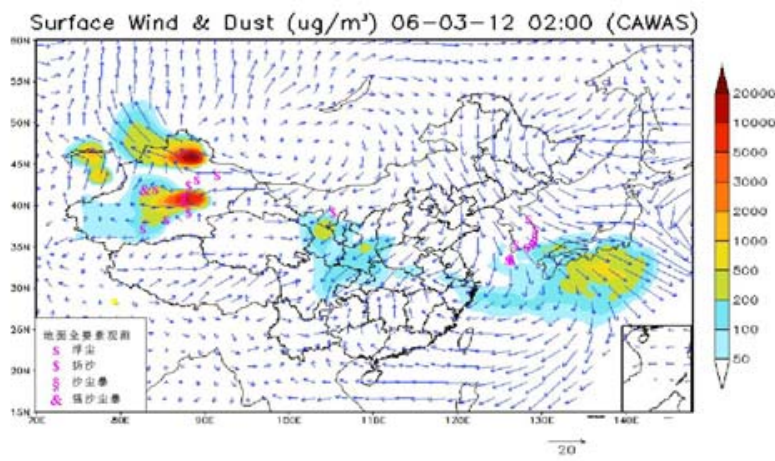

Fig. 4. Surface snap SDS concentrations and wind field at (a) $20 \mathrm{~h}$ on $9 \mathrm{March}$, (b) $14 \mathrm{~h}$ on $10 \mathrm{March}$, (c) $20 \mathrm{~h}$ on $10 \mathrm{March}$, (d) $14 \mathrm{~h}$ on 11 March, (e) $20 \mathrm{~h}$ on $11 \mathrm{March}$, and (f) $2 \mathrm{~h}$ on 12 March from the outputs by the initial forecast time of $8 \mathrm{~h}$ on $9 \mathrm{March}$ (BST).

days but the difference of these three mean values was not as significant as in the dusty days.

Ejilaqi in the Badain Juran Desert recorded thirteen SDS processes during spring 2006 as shown in Fig. 6b. The time series forecasted by FT1, FT2 and FT3 agreed very well with those of PM10 observations in terms of both the time of each dust storm and concentrations except for DS19 with a gap of about $100 \mu \mathrm{g} \mathrm{m}^{-3}$ by FT1. Compared with Tazhong, CUACE/Dust performed better at Ejilaji where dust concentrations were much higher, which suggest that it was able to capture large synoptic SDS processes.
There were also thirteen SDS processes influencing Zhurihe, a station in the west of Onqin Daga sandy areas (Fig. 6c) in the east of Inner Mongolia. Like the case in Ejilaqi, the forecasting results matched reasonably with the PM10 observations. FT1 showed some under-predictions in DS4, DS7, DS9, DS17, DS28 and DS29 with much better results than FT2 and FT3 in the first four cases but not in the last two. As the surface concentration of Zhurihe is controlled by both local emissions and transports from the upstream arid areas in Mongolia, the under-estimates might indicate some weakness in CUACE/Dust system in accurately predicting local emissions in these source areas or long-range transports from Mongolia. 


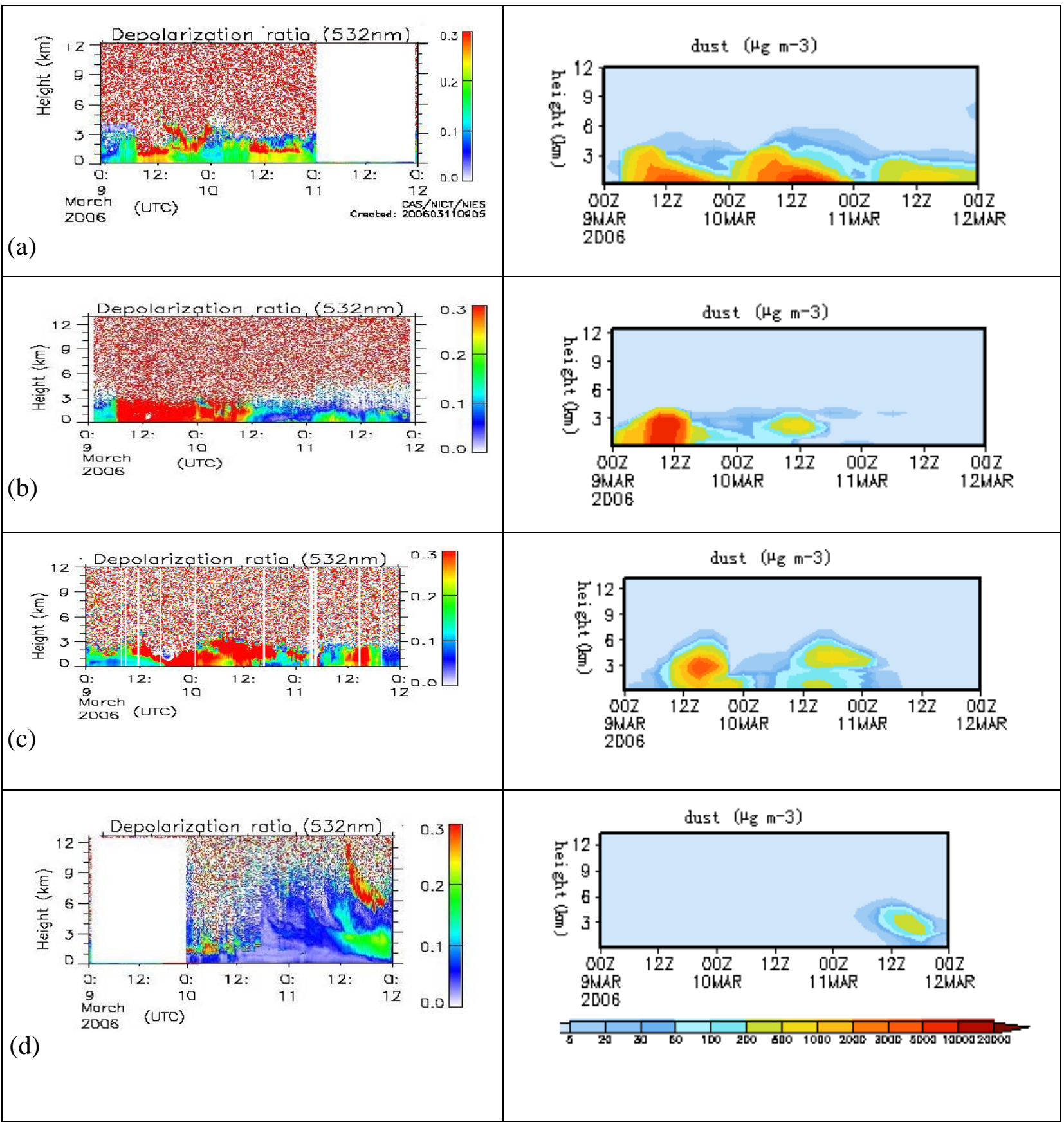

Fig. 5. Time series of lidar depolarization ratio (left) and predicted vertical concentration plot from 9 March $00 \mathrm{Z}$ to $12 \mathrm{March} 00 \mathrm{Z}$ (right) for (a) Shapotou, (b) Huhhot, (c) Beijing and (d) Tskuba respectively.

Nine SDS processes to Beijing were observed in spring of 2006 (Fig. 6d). The model was able to predict most of the SDS processes hitting Beijing but the predicted dust concentrations were smaller than those of PM10 observation in six SDS cases, i.e. DS4, DS7, DS9, DS13, DS19 and DS28. The mean values for FT1, FT2 and FT3 were 56, 44, $34 \mu \mathrm{g} \mathrm{m}^{-3}$ respectively while the spring mean PM10 concen- tration was $172 \mu \mathrm{g} \mathrm{m}^{-3}$. Most of the surface dust particles in Beijing might be transported from the source areas north or northwest to Beijing from Inner Mongolia during dust events. However, as the local fugitive dust sources such as the road dusts and construction activities in Beijing were not included in the model, an under-estimate by CUACE/Dust and a larger gap were expected considering the fact that local 
(a)

(b)

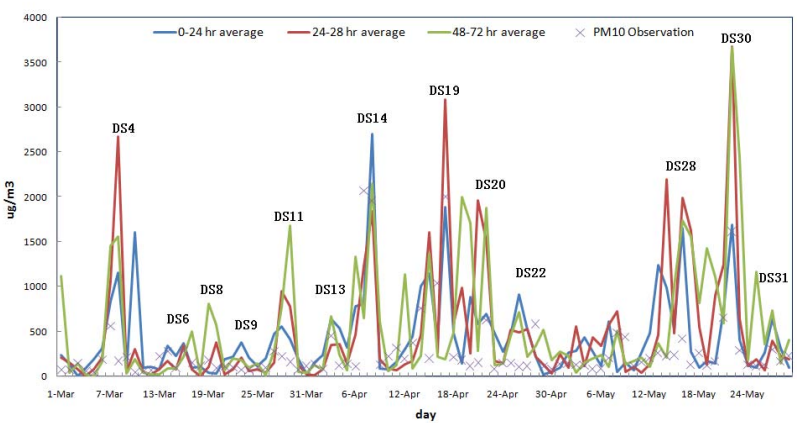

(c)

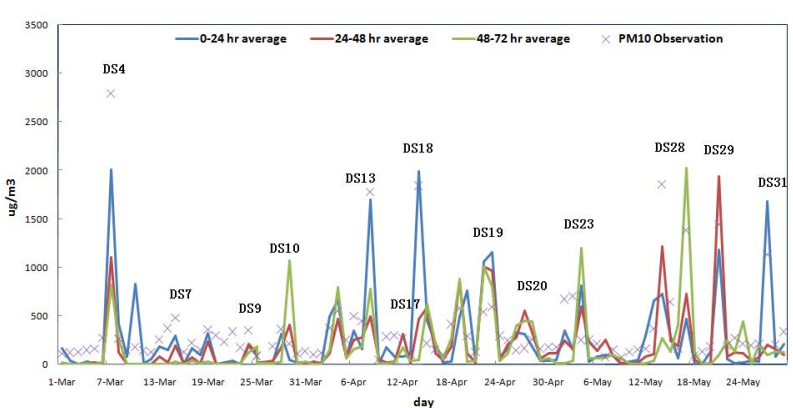

(d)

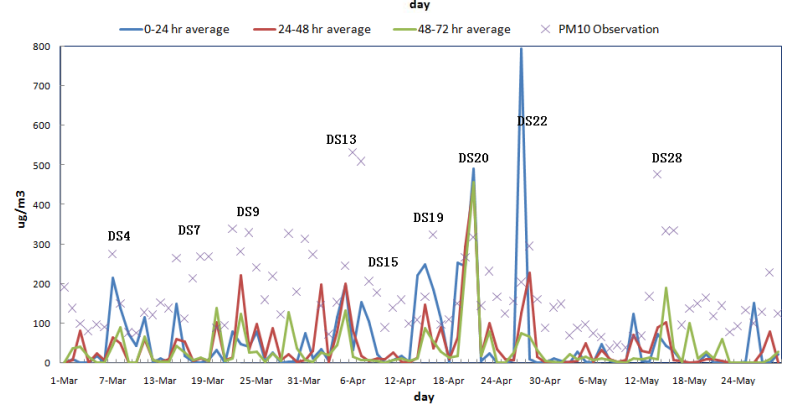

(e)

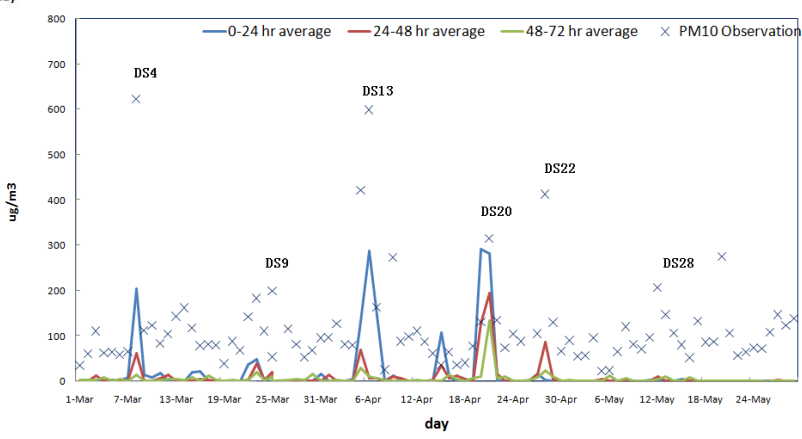

Fig. 6. Comparisons of the surface 24-h mean SDS concentration by 0-24h (FT1), 24-48h (FT2) and 48-72h (FT3) forecasts and the surface PM10 observation for the entire spring from 3 March to 31 May for (a) Tazhong, a station in central part of Takilimakan Deserts in Xinjiang province in China, (b) for Ejilaqi, a station in the north of Badain Juran deserts, (c) for Zhurihe, a station in the west of Onqin Daga sandy areas, (d) for Beijing, a station away from SDS source area, and (e) for Dalian, a station away from SDS source areas and in the west coast of the Bohai sea, respectively. DS xx, such as DS 4, means SDS process number defined in Table 1.

PM concentration at Beijing has an annual average of about $142 \mu \mathrm{g} \mathrm{m}^{-3}$ (Beijing-EPA, 2006).

Dalian has witnessed six SDS processes in 2006, i.e. DS4, DS9, DS13, DS20, DS22 and DS28 (Fig. 6e). Like the SDS in Beijing, the time series of FT1, FT2 and FT3 were reasonably coherent to those of the PM10 observation while all the 6 cases were under-predicted with DS28 missed. The biggest gap was about $419 \mu \mathrm{g} \mathrm{m}^{-3}$ in DS4 without considering the average PM10 concentration of about $100-150 \mu \mathrm{g} \mathrm{m}^{-3}$ in a non-dusty day by local aerosol contributions (Air pollution Annual report from EPA). FT1 did much better than FT2 and FT3 for the first four dust episodes with much less underestimates.

It should be pointed out here that the comparison of predicted DM40 with the observed PM10 serves to qualitatively evaluate the trend and variation of the CUACE/Dust fore-
Table 3. Mean TS scoring for CUACE/Dust in 2006 spring time.

\begin{tabular}{lccc}
\hline Forecast Length & $0-24 \mathrm{~h}$ & $24-48 \mathrm{~h}$ & $48-72 \mathrm{~h}$ \\
\hline threat score & 0.31 & 0.23 & 0.21 \\
miss ratio & 0.48 & 0.62 & 0.65 \\
false alarm ratio & 0.55 & 0.6 & 0.6 \\
accuracy & 0.88 & 0.87 & 0.87 \\
\hline
\end{tabular}

casts as PM10 was not contributed by dust only, especially in the polluted areas far away from dust sources and DM40 contained larger dust particles than PM10. 


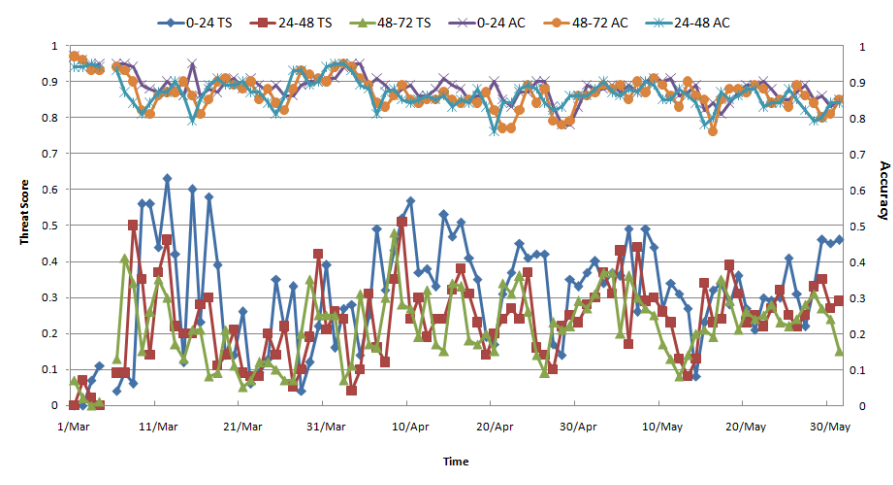

Fig. 7. Threat Scores and accuracy of $0-24 \mathrm{~h}, 24-48 \mathrm{~h}$ and $48-72 \mathrm{~h}$ forecasts for CUACE/Dust in 2006 spring.

\subsection{Overall evaluation of spring 2006 forecasts}

Threat score has been used to evaluate SDS forecast (Alpert et al., 2002) where the mean TS for $12 \mathrm{~h}$ to $36 \mathrm{~h}$ forecasts using various initial concentrations ranged from 0.17 to 0.47 . From the comparison of the forecast results with observations, this study found that a value of TS above 0.20 can be rendered acceptable for a reasonable SDS forecast. In regular weather forecasts, a TS value of 0.18 for the moderate rain is considered an acceptable forecast. Figure 7 shows the daily TS and Forecast Accuracy by three lead time forecasts in spring 2006. Majority of the TS is in the range of 0.1 to 0.6 for all three forecasts. Overall, the average TS value from 1 March to 31 May 2006 is 0.31 for FT1 and decreases to 0.23 and 0.21 for FT2 and FT3 (Table 3). It is also found that the TS is generally better for SDS days than that for non-SDS days. For example, TS for the severe SDS process - DS4 of 9-12 March are 0.55, 0.34 and 0.29 for FT1, FT2 and FT3, respectively. For the eleven severe SDS processes, i.e. about $85 \%$ of all the thirteen severe SDS processes in spring of 2006, TS are above the spring average (Table 3) and some of them including DS4, DS5, DS13, DS15, DS16, DS19, DS23 and DS31 are much higher than the average score. The performance for SDS processes and blowing dust processes is slightly lower than that for the severe SDS processes but is still near or over the spring average level. For the entire spring, CUACE/Dust has achieved a forecast accuracy of $88 \%$ (Fig. 7).

The TS also has a spatial distribution. Figure 8 is the overall TS based on the entire spring $24 \mathrm{~h}$ forecast results interpolated on a $1^{\circ} \times 1^{\circ}$ grid. It is found that CUACE/Dust performed better in the source regions such as in the Taklimakan and Mongolian Gobi deserts with averaged TS greater than 0.7. In downwind regions including most of Northern and North-eastern China, TS ranges from 0.3 to 0.5 .

The data assimilation system played an important role by improving the spring mean TS for $24 \mathrm{~h}$ forecasts from 0.22 to 0.31 but its influence was weaker for $48 \mathrm{~h}$ and $72 \mathrm{~h}$ forecasts. Analysis of the 2006 forecast results revealed that other fac-

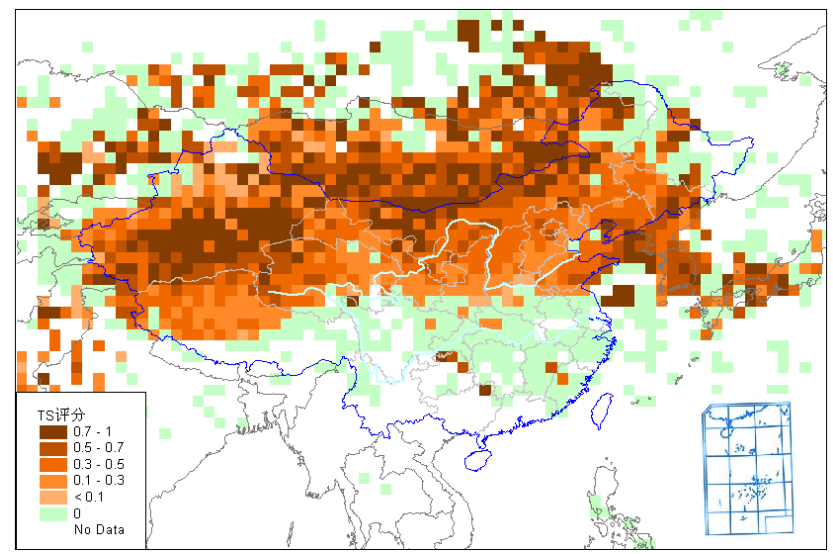

Fig. 8. Spring average threat score for each grid in the results domain.

tors are also critical to achieve a good performance. It is found that the high TS associated with severe SDS processes was due to the realistic forecasts of the synoptic patterns from the meteorological model.

The evaluation scores are also influenced by the quality and availability of the observation data. Both routine weather and satellite observations of SDS are available only during the day time. Most dust emission has an apparent diurnal cycle in the source areas, beginning in the morning and reaching the maximum in the afternoon and weakening thereafter. When a SDS system reaches Northern China plane, it is usually at night or early morning when few SDS reports were available to compare with the forecast results. This may partially explain the lower TS in the Northern China plane (Fig. 8). There are also other reasons for the lower TS. After a SDS process reaches Northern China plain with weaker surface winds, it is rather difficult to distinguish a floating dust record from the haze record which has been also defined by visibility less than $10 \mathrm{~km}$. Some of the SDS processes may be reported as haze in the pollution areas. This may partially explain the lower TS in the Northern China plane than that of Korea and Japan. Clearly, more reliable data sets are required in the further evaluations of SDS models.

\section{Conclusions}

CUACE/Dust, an operational SDS forecasting system with a 3-Dvar data assimilation system, was utilized for the 2006 spring SDS forecasts in East Asia. Its robust forecast ability has been demonstrated through predicting a heavy SDS process in 8-12 March by comparing with the surface concentrations and synoptic SDS records. CUACE/Dust successfully captured the production and evolution of this process in East Asia. Comparisons with the surface lidar measurements indicated that the model also reasonably simulated the vertical structure of SDS during this dust process. 
For all the SDS processes in spring 2006, time series of model predictions for DM40 were evaluated against PM10 observations at 5 representative stations. It was shown that the model was able to catch the majority of the dust events that occurred even with local dusty days although with some under-estimates in Takalimakan and Onqin Daga sandy areas.

The forecasting system's overall behaviour has been verified by a TS scoring system and the spring average threat score is $0.31,0.23$ and 0.21 for the $24 \mathrm{~h}, 48 \mathrm{~h}$ and $72 \mathrm{~h}$ forecasts. Averaged TS in source regions such as in the Taklimakan and Mongolian Gobi deserts was greater than 0.7. In downwind regions including most of Northern and Northeastern China, TS ranges from 0.3 to 0.5 . TS for $85 \%$ severe SDS processes by three FTs are above the spring average value with $61 \%$ ones with relatively high scores. TS for $84 \%$ of all the 31 SDS processes are also above the spring average score.

CUACE/Dust has shown some weakness in the prediction of SDS in Mongolia as no detailed soil data and observations are available over there. More work should be done to upgrade all of these for more accurate forecasts. There is also some work that should be done as to the SDS observation, especially to the vertical observation which is rare but vital to model initializations and verifications.

Acknowledgements. The authors wish to thank for the financial supports from the MOST (2004DIB3J115) and the National Basic Research Program (973) (2006CB403703 and 2006CB403701) of China for this project.

Edited by: H. Wernli

\section{References}

Alfaro, S. C., Gaudichet, A., Gomes, L., and Maillé, M.: Modeling the size distribution of a soil aerosol produced by sandblasting, J. Geophys. Res, 102, 11 239-11 249, 1997.

Alfaro, S. C. and Gomes, L.: Modeling mineral aerosol production by wind erosion: Emission intensities and aerosol size distribution in source areas, J. Geophys. Res., 106, 18 075-18 084, 2001.

Alpert, P., Krichak, S. O., Tsidulko, M., Shafir, H., and Joseph, J. H.: A dust prediction system with toms initialization, Mon. Weather Rev., 130, 2335-2345, 2002.

Beijing-EPA: Annual report of environment in beijing, 2006 (in Chinese).

Gong, S. L., Barrie, L. A., Blanchet, J.-P., Salzen, K. v., Lohmann, U., Lesins, G., Spacek, L., Zhang, L. M., Girard, E., Lin, H., Leaitch, R., Leighton, H., Chylek, P., and Huang, P.: Canadian aerosol module: A size-segregated simulation of atmospheric aerosol processes for climate and air quality models 1. Module development, J. Geophys. Res., 108, 4007, doi:4010.1029/2001JD002002, 2003a.

Gong, S. L., Zhang, X. Y., Zhao, T. L., McKendry, I. G., Jaffe, D. A., and Lu, N. M.: Characterization of soil dust distributions in china and its transport during ace-asia 2.
Model simulation and validation, J. Geophys. Res., 108, 4262, doi:4210.1029/2002JD002633, 2003b.

Gong, S. L., Zhang, X. Y., Zhao, T. L., Zhang, X. B., Barrie, L. A., McKendry, I. G., and Zhao, C. S.: A simulated climatology of asian dust aerosol and its trans-pacific transport. Part ii: Interannual variability and climate connections, J. Climate, 19, 104-122, 2006.

Gong, S. L. and Zhang, X. Y.: CUACE/Dust - an integrated system of observation and modeling systems for operational dust forecasting in Asia, Atmos. Chem. Phys. Discuss., 7, 10323-10342, 2007.

Hong, S.-Y. and Pan, H.-1.: Nonlocal boundary layer vertical diffusion in a medium-range forecast model, Mon. Weather Rev., 124, 2322-2339, 1996.

Hu, X. Q., Lu, N. M., Niu, T., and Zhang, P.: Operational retrieval of Asian sand and dust storm from FY-2C geostationary meteorological satellite and its application to real time forecast in Asia, Atmos. Chem. Phys. Discuss., 7, 8395-8421, 2007, http://www.atmos-chem-phys-discuss.net/7/8395/2007/.

IPCC: Climate change 2007: The physical science basis, contribution of working group $i$ to the fourth assessment report of the intergovernmental panel on climate change, edited by: Forster, P., Ramaswamy, V., Artaxo, P., Berntsen, T., Betts, R., Fahey, D. W., Haywood, J., Lean, J., Lowe, D. C., Myhre, G., Nganga, J., Prinn, R., Raga, G., Schulz, M., and Dorland, R. V., Cambridge University Press, 2007.

Marticorena, B. and Bergametti, G.: Modeling the atmospheric dust cycle. Part 1: Design of a soil-derived dust emission scheme, J. Geophys. Res., 100, 16415-16430, 1995.

Niu, T., Gong, S. L., Zhu, G. F., Liu, H. L., Hu, X. Q., Zhou, C. H., and Wang, Y. Q.: Data assimilation of dust aerosol observations for cuace/dust forecasting system, Atmos. Chem. Phys. Discuss., 7, 8309-8332, 2007, http://www.atmos-chem-phys-discuss.net/7/8309/2007/.

Pe'rez, C., Nickovic, S., Baldasano, J. M., Sicard, M., Rocadenbosch, F., and Cachorro, V. E.: A long saharan dust event over the western mediterranean: Lidar, sun photometer observations, and regional dust modeling, J. Geophys. Res., 111, D15214, doi:10.1029/2005JD006579, 2006.

Qian, Z. A., Hu, Y. Q., Gong, N. H., Wang, J. M., and Zhang, D. F.: Reports and analysis of the most severe sds "93.5.5", Research of China SDS, 37, 1996.

Shao, Y.: A model for mineral dust emission, J. Geophys. Res., 106, 20 239-20 254, 2001.

Shao, Y.: Simplification of a dust emission scheme and comparison with data, J. Geophy. Res., 109, D10202, doi:10.1029/2003JD004372, 2004.

Smolarkiewicz, P. K.: Multidimensional positive definite advection transport algorithm: An overview, International Journal for $\mathrm{Nu}-$ merical Methods in Fliuds, 50, 1123-1144, 2006.

Sugimoto, N., Matsui, I., Liu, Z., Atsushi Shimizu, Tamamushi, I., and Asai, K.: Observation of aerosols and clouds using a twowavelength polarization lidar during the nauru99 experiment, Sea and Sky, 76, 93-98, 2000.

Sun, J. M., Zhang, M. Y., and Liu, T. S.: Spatial and temperal characteristics of dust stroms in china and its surrouding regions, 1960-1999: Relations to source area and climate, J. Geophy. Res., 106, 10325-10334, 2001.

Tegen, I. and Fung, I.: Modeling of mineral dust in the atmosphere: 
Sources, transport, and optical thickness, J. Geophys. Res., 99, 22 897-22 914, 1994.

Uno, I., Amano., H., Emori, S., Kinoshita, N., Matsu., I., and Sugimoto, N.: Trans-pacific yellow sand transport observed in April 1998: Numerical simulation, J. Geophys. Res., 106, 18331$18344,2001$.

Uno, I., Wang, Z., Chiba, M., Chun, Y. S., Gong, S. L., Hara, Y., Jung, E., Lee, S.-S., Liu, M., Mikami, M., Music, S., Nickovic, S., Satake, S., Shao, Y., Song, Z., Sugimoto, N., Tanaka, T., and Westphal, D. L.: Dust model intercomparison (dmip) study over asia: Overview, J. Geophys. Res., 111, D12213, doi:12210.11029/12005JD006575, 2006.

Wang, Y. Q., Zhang, X. Y., Gong, S. L., Zhou, C. H., Hu, X. Q., Liu, H. L., Niu, T., and Yang, Y. Q.: Surface observation of sand and dust storm in east Asia and its application in CUACE/Dust forecasting system, Atmos. Chem. Phys., 8, 545-553, 2008, http://www.atmos-chem-phys.net/8/545/2008/.

Yang, Y. Q., Hou, Q., Zhou, C. H., Liu, H. L.,Wang, Y. Q., and Niu, T.: A study on sand/dust storms over northeast Asia and associated large-scale circulations in spring 2006, Atmos. Chem. Phys., 8, 25-33, 2008, http://www.atmos-chem-phys.net/8/25/2008/.

Yumimoto, K., Uno, I., Sugimoto, N., Shimizu, A., and Satake, S.: Adjoint inverse modeling of dust emission and transport over east asia, Geophys. Res. Lett., 34, L08806, doi:08810.01029/02006GL028551, 2007.
Zhang, X. Y., An, Z. S., and Cao, J. J.: Dust emission from chinese desert sources linked to variations in atmospheric circulation, J. Geophys. Res., 102, 28 041-28 047, 1997.

Zhang, X. Y., Gong, S. L., Shen, Z. X., Mei, F. M., Xi, X. X., Liu, L. C., Zhou, Z. J., Wang, D., Wang, Y. Q., and Y. Cheng: Characterization of soil dust distributions in china and its transport during ace-asia 1. Net work measurements, J. Geophys. Res., 108, 4261, doi:4210.1029/2002JD002632, 2003.

Zhang, X. Y.: Sand/dust storms of the northest asia in the spring of 2006, China Meteorological Press, 2006.

Zhao, T. L., Gong, S. L., Zhang, X. Y., and McKendry, I. G.: Modelled size-segregated wet and dry deposition budgets of soil dust aerosol during ace-asia, 2001: Implications for trans-pacific transport, J. Geophys. Res., 108, 8665, doi:8610.1029/2002JD003363, 2003.

Zhao, T. L., Gong, S. L., Zhang, X. Y., Abdel-Mawgoud, A., and Shao, Y. P.: An assessment of dust emission schemes in modeling east asian dust storms, J. Geophys. Res., 111, D05590, doi:10.1029/2004JD005746, 2006.

Zhou, Z. J.: Blowing-sand and sandstorm in china in recent 45 years, Quaternary Research (Chinese), 21, 9-17, 2001 (in Chinese). 